\title{
SABERES DA EXPERIÊNCIA DE ESTUDANTES JOVENS E ADULTOS: CONHECER PARA VALORIZAR
}

\author{
Maria Izabel Costa da Silva1, Rony Cláudio de Oliveira Freitas ${ }^{2}$ \\ Pós-graduação Lato Sensu em PROEJA, Instituto Federal do Espírito Santo \\ E-mail: mariaizabel@ifes.edu.br, freitasrco@gmail.com
}

\section{RESUMO}

Este artigo relata o Trabalho de Conclusão de Curso (TCC) desenvolvido no curso de Especialização do Programa Nacional de Integração Profissional com a Educação Básica na Modalidade de Educação de Jovens e Adultos (PROEJA), que teve como motivação a inquietação em relação à valorização de experiências trazidas por estudantes jovens e adultos no curso Desenhista Auxiliar Cadista, promovido pelo Instituto Federal do Espírito Santo (Ifes) e Secretaria Municipal de Educação do município de São Mateus. Para isso buscou-se referência em Jacques Rancière, Ole Skovsmose e Paulo Freire, além de outros autores da Educação de Jovens e Adultos (EJA). Os resultados obtidos a partir de grupos focais envolvendo estudantes e professores apontam para a ideia de que estudantes jovens e adultos, quando têm suas vivências e conhecimentos valorizados e articulados aos conteúdos escolares, abrem-se a um processo de aprendizagem mais significativo e, portanto, mais duradouro.

Palavras-chaves: PROEJA; Conhecimento; Ensino; Aprendizagem.

\section{INTRODUÇ̃̃o}

A finalidade desse esforço teórico é resgatar uma discussão que tem a ver com a aparente obviedade da relação entre os sujeitos envolvidos no processo de ensino-aprendizagem: um sabe e o outro não. Já há alguns séculos filósofos e educadores apontam para a necessidade de protestar contra a naturalização da ideia de que a escola é o lugar de domínio de todos os conhecimentos válidos produzidos pela humanidade e necessários a todos os homens, sendo, portanto a única com autoridade para socializá-los. Neste modelo, notase que as histórias e trajetórias de vida dos sujeitos, bem como seus anseios e desejos, cultura, hábitos e valores, não são considerados no momento em que se planejam os currículos e os métodos didáticopedagógicos, gerando um distanciamento conflituoso entre as expectativas dos professores e dos estudantes no que diz respeito à aquisição de novos conhecimentos.

Justificamos a importância de estudar essa realidade visto que as dificuldades enfrentadas pelos estudantes refletem-se em reprovação e evasão, além de desestímulo ou indiferença do professor ao vê-los tão desinteressados, e, assim, grande potencial humano é desperdiçado.

Em meio a essas inquietações, a questão de pesquisa foi forjada buscando saber se a valorização das experiências dos educandos nas práticas pedagógicas contribui como fator facilitador da aprendizagem, tendo como objetivo geral investigar como essas experiências e saberes dos estudantes são considerados por eles mesmos e pelos professores do PROEJA Formação Inicial e Continuada (FIC) São Mateus, na relação com a aprendizagem dos conteúdos específicos das disciplinas.

Partimos do pressuposto desenvolvido por Paulo Freire (1971) de que os educadores/as, ao partirem da realidade concreta e das experiências vivenciadas pelos educandos, no diálogo permanente dos conhecimentos de ambos, geram um ambiente de comunicação de saberes e não de sobreposição de uns sobre outros, tornando as aprendizagens mais significativas e conscientes. Compreendemos que reconhecer as experiências de vida dos educandos e os conhecimentos adquiridos por eles em vivências escolares anteriores e não-escolares como saberes tão relevantes e válidos quanto aqueles sistematizados acadêmica e cientificamente, é reconhecer que, educador e educandos, ambos, igualmente, são seres cognoscentes e como tal têm capacidade de ensinar e aprender.

\footnotetext{
${ }^{1}$ Pedagoga do Ifes campus São Mateus; Aluna da Especialização em PROEJA do Ifes campus São Mateus; E-mail: mariaizabel@ifes.edu.br

${ }^{2}$ Doutor em Educação, professor do Instituto Federal do Espírito Santo campus Vitória; Email: freitasrco@gmail.com
} 


\section{Procedimentos Metodológicos}

\section{Pesquisa}

Esta pesquisa surge no contexto de implantação de cursos de PROEJA nas instituições federais de educação profissional, como um programa de Governo que incentiva tais instituições a abrirem espaço para a profissionalização de uma camada da população que, historicamente, encontra-se excluída dos processos educativos formais de educação básica e de qualificação para o trabalho: os jovens e adultos das classes populares. No Ifes campus São Mateus a opção foi a oferta de cursos de PROEJA FIC. Neste curso os jovens e adultos cursam as séries finais do Ensino Fundamental nas escolas da Rede Municipal de Educação e a qualificação profissional no Ifes campus São Mateus.

Pensar o atendimento educacional do público-alvo a que se destina o programa requer um aprofundamento de quem são estes sujeitos e quais propostas pedagógicas são mais adequadas para atendêlos, para isso é necessário o estudo e a discussão permanentes. É neste campo das práticas pedagógicas que esta pesquisa quer contribuir.

Adotamos como metodologia a pesquisa qualitativa por entendermos ser a mais adequada para o alcance de nossos objetivos. A pesquisa qualitativa, como método investigativo nas ciências sociais, e da pesquisa em educação em especial, considera as relações e contextos nos quais estão inseridos os sujeitos envolvidos na pesquisa, bem como sua história. "Ela incorpora o que os participantes dizem, suas experiências, atitudes, crenças, pensamentos e reflexões, tal e como são expressadas por eles mesmos." (GONZAGA apud PIMENTA, 2006 p.70) Pelo próprio fato de o tema da pesquisa estar relacionado, antes de tudo, a concepções, imaginários, olhares de um grupo específico, não caberia adotar métodos quantitativos. D’Ambrosio (apud JORDANE, 2007, p.54) localiza a pesquisa qualitativa como ideal quando se tem esse intuito, pois "lida e dá atenção às pessoas e às suas ideias, procura fazer sentido de discursos e narrativas que estariam silenciosas".

\section{Coleta e análise de dados}

Nesta pesquisa escolhemos a realização de grupos focais. O grupo focal é um espaço de relato e debate de ideias, opiniões e experiências. É planejado e coordenado pelo pesquisador e se realiza com um grupo de pessoas (os sujeitos da pesquisa) que possuem algumas características em comum, relacionadas ao assunto que se pretende pesquisar. Estas pessoas são provocadas pelo mediador - por meio de perguntas e questões - que em seguida suscita um diálogo aberto e organizado. Todos os relatos são registrados a fim de que se gere uma fonte de dados e informações para a pesquisa.

Por se tratar de um trabalho que destaca em seu referencial teórico autores que defendem uma educação pautada no diálogo, desejamos também, no processo investigativo, adotar uma metodologia que preservasse esse princípio. E o grupo focal não apenas permite o diálogo como depende dele para que seja efetivo, pois objetiva desvelar experiências, sentimentos, percepções, preferências que são despertados e explicitados à medida que um sujeito identifica (ou não) suas histórias com as dos outros sujeitos. Todos os grupos focais foram gravados em áudio e vídeo, bem como registrados manualmente por duas relatoras. Além disso, os participantes responderam a um questionário socioeconômico que complementou a busca de dados.

\section{Sujeitos envolvidos}

A partir dos objetivos da pesquisa, definimos os sujeitos a serem pesquisados, que não poderiam ser outros a não ser educadores e educandos da EJA. Por se tratar de uma pesquisa forjada no curso de Especialização em PROEJA, escolhemos um curso de qualificação deste mesmo programa, o PROEJA FIC Desenhista Auxiliar - Cadista do Ifes campus São Mateus. A cada semestre dois professores da área técnica e sete da formação geral lecionam para este curso que, em 2010-01, semestre da realização da pesquisa, correspondia a uma turma de sexta série e contava com 12 alunos matriculados com frequência regular.

O grupo focal realizado com educadores contou com a participação de quatro educadores, dois homens da área técnica (Informática, Desenho Técnico e CAD) e duas mulheres da formação geral (Língua Portuguesa e Matemática). As professoras da formação geral têm mais de 15 anos de docência. Todos têm menos de cinco anos de docência na Educação de Jovens e Adultos e menos de dois na educação profissional.

No grupo focal realizado com estudantes tivemos também duas mulheres (18 e 28 anos) e dois homens (17 e 34 anos). Apenas um estudante nunca trabalhou. Quanto à escolaridade há diversidade. Dois estudantes concluíram o ensino médio, sendo um deles por meio da prova do Exame Nacional para Certificação de Competências de Jovens e Adultos (ENCCEJA). Os outros dois não concluíram o Ensino Fundamental, tendo um terminado 4a série e outro a 7aㅡ série (hoje denominados quinto e oitavo anos, respectivamente). 


\section{DESENVOLVIMENTO}

Pretende-se agora analisar todos os dados coletados à luz dos referenciais teóricos que embasam este trabalho.

\section{Conhecimentos, experiências e aprendizagens dos sujeitos da EJA}

Ao se tratar de um programa que atende especificamente ao público da EJA, consideramos importante buscar, nos estudos sobre essa modalidade, elementos que nos ajudem a entender quem são estes sujeitos e seus processos de aprendizagem, acreditando ser este o melhor caminho no desafio de elaborar propostas pedagógicas que venham ao encontro de suas especificidades.

Oliveira (2001) localiza estes sujeitos basicamente em três condições peculiares: a condição de nãocrianças, a condição de excluídos da escola e a condição de membros de determinados grupos culturais.

Sobre a condição de não-crianças, um ponto comum entre os sujeitos jovens e adultos que os diferencia em relação à infância e à adolescência é a participação no mundo do trabalho. Por pertencerem ao grupo denominado economicamente ativo, esses sujeitos, na maioria das vezes, já desempenham alguma atividade laboral ou estão à procura. Estão alocados majoritariamente em postos de baixa remuneração do mercado formal quando não, pela condição de desempregados, desenvolvem alguma atividade no setor informal. Segundo Kuenzer (2009), para este grupo de trabalhadores empregados ou desempregados, a escola é um dos únicos espaços que podem promover o acesso aos conhecimentos necessários para compreender e reverter relações sociais produtoras desta realidade de exclusão e promover sua inserção na sociedade de modo mais justo. Segundo Oliveira (2001), estes sujeitos guardam em comum também as experiências em situações diversas no mundo do trabalho e outras vivências fora do âmbito da família, ampliando, assim, suas percepções sobre o trabalho, os relacionamentos, as decisões a serem tomadas e as instituições sociais em geral. Isso tudo os coloca em posição de extremo potencial para a aprendizagem. Na verdade, todas as situações experenciadas são, em si, momentos de aprendizagem profunda:

O adulto está inserido no mundo do trabalho e das relações interpessoais de um modo diferente daquele da criança e do adolescente. Traz consigo uma história mais longa (e provavelmente mais complexa) de experiências, conhecimentos acumulados e reflexões sobre o mundo externo, sobre si mesmo e sobre outras pessoas. Com relação à inserção em situações de aprendizagem, essas peculiaridades da etapa de vida em que se encontra o adulto fazem com que ele traga consigo diferentes habilidades e dificuldades (em comparação à criança) e, provavelmente, maior capacidade de reflexão sobre o conhecimento e sobre seus próprios processos de aprendizagem (OLIVEIRA, 2001, p. 18).

Essas percepções e formas de viver, resultantes das aprendizagens ocorridas em todos os espaços e períodos vividos, dentro e principalmente fora da escola. Conforme Soligo (2010), esses conhecimentos devem constituir o contexto escolar de ensino aprendizagem afinal,

A aprendizagem não é resultado apenas de ações pedagógicas especialmente planejadas: a partir do momento em que nasce, o ser humano começa a aprender, tanto o que lhe é ensinado de forma intencional como o que pode aprender pelo simples fato de estar vivo, convivendo com outras pessoas em ambientes sociais diversificados. Muitas coisas que sabemos não nos foram formalmente ensinadas (SOLIGO, 2010).

Estes saberes guardam em si informações de natureza empírica, dotam seus possuidores de determinadas habilidades práticas que só podem ser adquiridos por meio do exercício e da vivência. Guardam também uma ciência própria, do real concreto, do fazer, que se relacionam com outras ciências, com conhecimentos sistematizados academicamente, tendo, portanto, o potencial de articular-se aos conteúdos escolares. Freire (1987) nos estimula a refletir sobre esse tema, quando afirma que a escola não consegue dar a dimensão libertadora e igualitária à relação professor-aluno e, por conseguinte, às práticas educativas, por estar baseada numa concepção bancária de educação, em que o educador aparece como narrador indiscutível que repassa "conteúdos que são retalhos da realidade desconectados da totalidade em que se engendram e em cuja visão ganhariam significação". (FREIRE, 1987, p. 57) Dessa forma, não é permitido ao educando dizer suas palavras, produzidas em suas realidades e sentidos, aprendizagens, constatações, e que em determinados momentos de estímulo são resgatados e associados a outros conhecimentos, proporcionando a compreensão e memorização de novas informações (FONSECA apud FREITAS, 2010). 
Skovsmose (2001, p.18) corrobora com Freire (1987) ao retomar os princípios da Educação Crítica, defendendo que "o processo educacional deve ser entendido como diálogo." Primar pela igualdade de saberes na relação entre educadores e educandos, portanto, significa praticar a democracia dentro dos espaços educativos, pois, se é esperado que a escola forme indivíduos para o exercício da democracia, é necessário que o próprio ambiente escolar seja democrático. O que importa nesse exercício de diálogo é a aceitação de que o conhecimento não se dá em via única, é o respeito ao saber do outro. Precisamos ter consciência de que na educação de jovens e adultos as experiências são tão importantes quanto as expectativas, diferentemente da educação de crianças, em que na maioria das vezes é preciso criar um contexto imaginário para exemplificar alguma situação real (FREITAS, 2010).

Outra característica em comum dos sujeitos da EJA elencada por Oliveira (2001) é a condição de excluídos da escola. Oriundos, em grande parcela, de famílias rurais de baixa ou nenhuma escolaridade, procuram a escola a fim de concluir a escolaridade mínima exigida cada vez mais pelas empresas em qualquer que seja a função a ser desempenhada. O documento Educação de jovens e adultos: uma memória contemporânea publicada pela UNESCO vem, assim, delineando o público-alvo da EJA:

Trata-se de um jovem ou adulto que historicamente vem sendo excluído, quer pela impossibilidade de acesso à escolarização, quer pela sua expulsão da educação regular ou mesmo da supletiva pela necessidade de retornar aos estudos. Não é só o aluno adulto, mas também o adolescente; não apenas aquele já inserido no mercado de trabalho, mas o que ainda espera nele ingressar; não mais o que vê a necessidade de um diploma para manter sua situação profissional, mas o que espera chegar ao ensino médio ou à universidade para ascender social e profissionalmente (UNESCO, 2004, p. 19).

Articulando essa realidade ao âmbito mais amplo das políticas educacionais brasileiras ao longo dos nossos pouco mais de 500 anos, podemos demarcar historicamente as causas dessa exclusão.

Quanto aos adultos, que tiveram pouca ou nenhuma passagem pelos bancos escolares, compondo faixa etária a partir dos 30 anos, podemos dizer que suas experiências escolares localizam-se num período da história da educação brasileira em que o acesso ao ensino fundamental, especialmente nas zonas rurais, era restrito. As escolas eram poucas, reduzindo a quantidade de vagas disponíveis e muitas vezes eram distantes das casas dos estudantes. Além disso, era cultural e até mesmo necessária, a participação das crianças no trabalho da roça em determinadas épocas do ano em que a demanda de serviço aumentava, ocasionando a ausência das crianças às aulas durante este período. Com a vida escolar marcada por essa descontinuidade, ao final da segunda ou terceira tentativa de cursar pelo menos algumas séries do chamado primário, os pais acabavam por desistir da ideia de enviar seus filhos à escola (UNESCO, 2004). Em se tratando de mulheres então, na maioria das vezes, sequer era aceito que frequentassem a escola por um período mínimo que fosse. A falta de estrutura física, de vagas e de propostas escolares, que dessem conta dessas questões, resultou em milhões de adultos que hoje são analfabetos ou com pouquíssima escolaridade.

Os jovens por sua vez, nascidos a partir da década de 90, iniciaram suas trajetórias escolares em época da universalização do ensino fundamental, que ocorreu a partir dessa mesma década. A ampliação de vagas, contemplando um média 97\% das crianças e adolescentes entre 7 e 14 anos, contudo, não veio acompanhada de infra-estrutura adequada, de profissionais qualificados e de outras ações necessárias à garantia do atendimento satisfatório às diferentes necessidades das crianças e dos adolescentes. Estes passam a ter trajetórias escolares mais longas, mas igualmente conturbadas. Ingressando muito cedo na escola, esses alunos, por diversos motivos (de socialização, condição sócioeconômica, questões psicológicas, envolvimento com atividades ilegais ou mesmo dificuldades com os conteúdos, avaliações e atividades) não se adaptam às regras, às rotinas e às propostas pedagógicas da escola tradicional, burlando-as e até mesmo confrontando aqueles que representam tais normativas, como professores, coordenadores, ou até mesmo colegas. Alguns destes jovens chegam a configurar-se como empecilho à ordem, à organização ou à qualidade da escola e má influência para os demais estudantes, sendo, sempre que possível, remanejados para os cursos noturnos, em que, acredita-se, causarão menos problemas e se adaptarão melhor (BRASIL, 2007).

Há também outra condição que caracteriza o jovem e o adulto da EJA e que, perpassando as condições anteriores (e talvez até as gere), localiza-o em situação de desvantagem diante da escola: o de pertencente a um determinado grupo cultural. As crianças, jovens e adultos das classes populares, encontram grandes obstáculos para sobreviverem ao modo como a escola está organizada, pois essa espera que todos os seus estudantes tenham perfil do público das classes economicamente favorecidas, com acesso aos bens culturais e materiais. Conteúdos, tempos, avaliação, espaços, atividades, olhares, nada está voltado para o atendimento 
da população trabalhadora, ou de seus filhos, logo é natural que esta não responda de forma esperada, o que é caracterizado como fracasso escolar (OLIVEIRA, 2001).

Freire (1987) critica a postura da escola em não partir da realidade dos educandos no momento de planejar as ações e práticas pedagógicas e alerta:

simplesmente, não podemos chegar aos operários, urbanos ou camponeses, estes de modo geral, imersos num contexto colonial, quase umbilicalmente ligados ao mundo da natureza de que se sentem mais partes que transformadores, para à maneira da concepção "bancária", entregar-lhes "conhecimento" ou impor-lhes um modelo de bom homem, contido no programa cujo conteúdo nós mesmos organizamos. (p.84)

Por ter suas peculiaridades culturais negligenciadas pelas instituições de ensino e, como consequência, não enquadrar-se ao padrão de sucesso, tal grupo carrega o estigma da incapacidade intelectual e do despreparo para as demandas do mercado de trabalho. Fica sempre, aos olhos da sociedade, na condição do não-saber, pois não teve "acesso aos conhecimentos socialmente valorizados e aos espaços reconhecidos da vida social" (ESTEBAN et al., 2001, p.8, grifo nosso). A posição de ignorância em que reside o imaginário sobre o estudante da EJA configura-se, geralmente como um fator que influencia em seu rendimento na escola, pois afeta diretamente sua autoconfiança e segurança de que é capaz, de que já é portador de muitos conhecimentos importantes, mas que, embora socialmente produzidos, pela lógica da hierarquização dos saberes, são marginalizados, não reconhecidos e não validados (ESTEBAN et al., 2001).

É claro que não podemos desconsiderar as histórias de indivíduos que superaram todas as dificuldades apresentadas anteriormente e alcançaram posições mais favoráveis na vida profissional e escolar. Isso se dá em geral porque, conforme Oliveira (2001) pondera, no plano objetivo estes sujeitos possuem características semelhantes e que os configura como um grupo mais ou menos homogêneo, demandando da escola políticas e práticas elaboradas a partir das características peculiares do grupo. Porém, no plano subjetivo a discussão é mais profunda, visto que, em se tratando de indivíduos com vivências e histórias de vida distintas, pensar a EJA exige também reflexão sobre o processo de desenvolvimento cognitivo e psicológico do adulto, tema pouco abordado na literatura e menos ainda nos planejamentos e formação dos profissionais.

A respeito dos sujeitos da EJA podemos inferir, a partir da leitura dos autores citados, que os sujeitos da EJA têm, em suas trajetórias individuais, diferentes tipos de vivências, desenvolvendo modos distintos e particulares de serem, dificuldades e capacidades que devem ser consideradas e tratadas de forma particular no âmbito do processo educativo. Porém, guardam entre si características comuns, dada sua condição de pertencentes a um mesmo grupo sócio-cultural. Tendo essas considerações em mente passemos a um outro momento de nossa reflexão.

\section{A escuta aos sujeitos: conhecendo para valorizar}

A primeira questão que nos instigou a promover a pesquisa foi saber se a valorização das experiências dos educandos nas práticas pedagógicas contribui como fator facilitador da aprendizagem. Em nossa busca consideramos importante perceber primeiramente a concepção dos sujeitos da pesquisa sobre o que é conhecimento.

Nas respostas de todos os participantes dos grupos focais, ficou evidente a ideia de que conhecimento são as habilidades e informações que adquirimos através das experiências e situações no decorrer de nossa vida e que, experiências aparentemente iguais ou repetidas, geram conhecimentos diferentes. As falas abaixo representam sínteses das opiniões expressadas durante a pesquisa:

"é aprendizagem que obtemos durante o decorrer da nossa vida, porque se você vai pruma empresa num vai ser a mesma experiência que você já tem em outra"... (ESTUDANTE L).

"passou por uma situação e teve um aprendizado com aquilo ou porque você acertou ou porque você errou, você aprendeu que aquilo ali é bom ou ruim, houve um aprendizado" (EDUCADOR B).

Observamos que educadores e educandos referem-se ao conhecimento não como algo exclusivamente científico ou restrito ao âmbito escolar, valorizando assim as experiências ligadas às relações humanas e sociais.

Resgatamos Freire (1971) neste diálogo sobre o conhecimento, pois ele faz a reflexão a respeito das diferentes formas como o ser humano se relaciona com o mundo e, nesta relação, conhece-o e transforma-o. Para ele é ingênuo considerar o conhecimento como algo estático e passível de ser transferido a alguém, visto 
que o ato de conhecer exige uma postura ativa, curiosa e transformadora das pessoas inseridas numa determinada realidade. Afirma ainda que "é como sujeito e somente enquanto sujeito, que o homem pode realmente conhecer" (FREIRE, 1971, p. 27). O conhecimento para ele dá-se por intermédio do próprio estar no mundo e da apropriação verdadeira daquilo que se vive, conhece, vê, aprende. Uma vez apreendido, este saber pode ser reinventado para aplicação em novas situações concretas. Assim, considera "a confrontação com o mundo como a fonte verdadeira do conhecimento." (FREIRE, 1971, p. 27)

Freire (1971) destaca um elemento importante nesse estar no mundo, com ele aprender e nele intervir: a busca constante. Aliamos esta discussão a uma afirmativa que se repetiu na fala dos educadores e educandos: a de que as pessoas aprendem quando têm vontade e interesse próprios, quando são curiosas, correm atrás, buscam aquilo que desejam ou precisam. Este pensamento fica expresso nas seguintes declarações:

\begin{abstract}
"se eu não tiver esse interesse né, próprio, essa vontade, essa convicção de me colocar pra fora, isso aí e entrar em ação e buscar isso aí, eu vou ser sincero, de nada adianta, é preciso ter o interesse próprio para que se aprenda" (ESTUDANTE M).

"só que o conhecimento, a pessoa automaticamente vai vivendo e vai adquirindo, só que quanto mais ela busca, mais curiosa que ela seja mais... com o tempo isso aí vai
\end{abstract} aumentando, lógico né, o conhecimento dessa pessoa" (ESTUDANTE).

"o querer, tem que querer conhecer pra ir atrás... ou querer ou precisa" (EDUCADOR B).

Outro autor que atribui à vontade, que brota do desejo ou da necessidade, valor significativo no processo de aprendizagem é Rancière (2005). Ele afirma que, tendo como pressuposto que todos os seres humanos possuem capacidade para aprender, portanto, inteligência, um fator pode ser determinante para se aprender algo ou não: é a vontade de aprender, que pode variar de acordo com as exigências e limitações que são postas diferentemente a uns e a outros. Para ele "ali onde a necessidade cessa, a inteligência repousa, a menos que uma vontade mais forte se faça ouvir e diga: continua" (RANCIÉRE, 2005, p. 79).

As opiniões dos educadores e educandos às perguntas feitas revelaram que os sujeitos de nossa pesquisa valorizam as aprendizagens e experiências que acumularam no decorrer da vida. Sendo assim, buscamos saber deles de que forma relacionam estes saberes àqueles trabalhados nas disciplinas escolares e se consideram que a valorização destes saberes, quando assumida nas práticas pedagógicas, colabora para uma melhor aprendizagem dos conteúdos.

A estes questionamentos educandos e educadores respondem com exemplos de suas próprias experiências, como as seguintes:

"To tendo conhecimento agora, buscando essas informações na teoria, eu já tenho essas informações na prática; porque na teoria né, eu tenho conhecimento, na prática também eu tenho conhecimento, então eu relaciono essas duas coisas né, há relacionamento em comum acordo porque uma coisa leva à outra, então eu to aprendendo agora na teoria o que eu já sei na prática" (ESTUDANTE M).

"alguns exercícios que eu separei pra iniciar esse conteúdo eu percebia que é...eles já tinham aquele conhecimento prático, mas como fazer...já tiveram contato visual com os resultados, mas como fazer ainda não...e isso foi a peça fundamental [...] Então esse contato que eles tiveram antes serviu nas atividades, serve como motivação até mesmo pra eles pra poder continuar no curso, continuar frequentando, não abandonar" (EDUCADOR JP).

Tais declarações podem estar indicando que os conteúdos ditos escolares e as aprendizagens do cotidiano, das situações já vivenciadas, apreendidas podem conter muitos conhecimentos em comum, mas que se apresentam em linguagens distintas. Os conteúdos escolares, geralmente, apresentam conotação mais teórica enquanto os do cotidiano são de cunho mais prático. À medida que se criam espaços de estímulo à socialização, interação entre eles, para que estes saberes escondidos nas histórias de vida dos educandos venham à tona e relacionem-se aos demais, a aprendizagem passa a ter mais sentido, torna-se mais significativa e duradoura. Em outras palavras, valoriza-se aquilo que o educando já conhece como conteúdo indispensável para o conhecimento de outros saberes ainda desconhecidos (FREIRE, 1970). Na medida em que o professor identifica essa possibilidade pode promover o encontro entre as experiências que os educandos trazem dos contextos que viveram (e vivem) e potencializar a participação destes estudantes de tal forma que 
a atividade educativa torna-se o mais significativa possível tanto para o professor, como, principalmente, para o educando, como afirma Piconez

[...] o professor pode mediar aprendizagens significativas, isto é, existe a possibilidade de intervenção pedagógica baseada nos conhecimentos prévios dos alunos, numa ampla gama de situações que podem levar à construção ou mesmo à reconstrução de conhecimento (PICONEZ, 2002, p. 87, grifo do autor).

O Documento Base do PROEJA (2007) assume como um dos seus princípios o respeito ao ser e aos saberes dos educandos, o que pode ser percebido na citação a seguir:

jovens e adultos trabalhadores possuem identidades e culturas particulares, forjadas por um conjunto de crenças, valores, símbolos, do mesmo modo, trazem uma gama de conhecimentos oriundos de sua formação anterior, da sua prática no trabalho e das suas vivências extra-trabalho. Todos esses saberes devem ser considerados no processo educativo, articulados com os novos conhecimentos que se produzem tanto no âmbito escolar, quanto no meio social, na perspectiva de aplicação prática (BRASIL, 2007, p. 29).

Nesse sentido, entendemos que a aplicação do princípio da valorização dos saberes no planejamento e nas práticas de sala de aula torna-se uma exigência feita aos educadores que se lançam na tarefa de pensar e fazer a Educação de Jovens e Adultos e a educação profissional. É importante considerar que a aprendizagem não ocorre naturalmente na medida em que um interlocutor repassa uma informação a um ouvinte, mas apenas quando este que escuta estabelece conexão entre aquilo que lhe foi dito e seus próprios interesses, crenças, valores, saberes, fazendo com que as informações recebidas de qualquer que seja o comunicador (televisão, amigos, família etc.) passe a ter sentido e significado (OLIVEIRA, 2009).

A partir desse entendimento, procuramos identificar se os sujeitos da pesquisa consideram as aulas em que as experiências são tomadas como parte integrante dos saberes a serem aprendidos e ensinados contribuem para uma maior possibilidade de aprendizagem. Para tanto, perguntamos aos professores se eles poderiam relatar situações em sala de aula em que foram incluídas/trabalhadas/utilizadas as experiências dos alunos, destacando se houve diferença das aulas convencionais. A seguir, selecionamos algumas respostas dos indivíduos.

aí eu percebi: ah, se é pra dar aula, não adianta você tentar passar certinho o que está no livro, tem que trabalhar o que o aluno quer aprender...aí fui começar a observar o que os alunos querem aprender?(EDUCADOR

quer dizer ponto sabe dividir, dinheiro sabe dividir, é assim, porque vem de uma vivência né, mais concreto (EDUCADORA B).

quando você tem um assunto e você vai pra abordar esse assunto e você consegue colocar algo prático, questão do dia a dia, eles conseguem captar melhor, do que você pegar "ah agora é teórico (EDUCADORA G).

a vivência deles facilitou a confeç̧ão desse material e eu acredito que confeccionar um material deve ter oportunizado uma aprendizagem maior, melhor, do que simplesmente ler, $e$ estudar...acho que partir pro concreto quando possivel facilita a aprendizagem (EDUCADORA B).

Para os educandos apresentamos duas situações bem distintas no que diz respeito à prática dos professores. A primeira situação descrevia uma aula bastante tradicional em que a dinâmica do professor limitava-se a explicar como se faz a divisão por um número. Já na segunda situação o professor trabalhava elementos da história da Matemática, que tinham a ver com o assunto, organizava em grupo a socialização das formas com que cada um costumava resolver problemas do seu dia a dia, envolvendo a divisão por um número, depois apresentava os resultados para o restante da turma, por fim, o professor fazia um paralelo entre as diversas formas de resolver a divisão por um número que havia surgido na sala e as formas de resolução mais utilizadas na linguagem escolar. Ao cabo da apresentação das situações, perguntamos aos estudantes através de qual delas eles sentiriam mais facilidade em aprender o referido assunto matemático. Todos os educandos afirmaram que na segunda situação, com certeza, teriam mais chances de aprender o conteúdo de uma forma mais fácil e significativa. Alguns motivos estão explicitados nas declarações abaixo. 
cada um tem um modo de pensar diferente, então eu acho que num diálogo entre eles, eu acho que eles desenvolve mais o conhecimento e resolve mais o problema...(ESTUDANTE A). taria ensinando mais os alunos a debater, a discutir formas de resolver, modos de aprender, trocando várias experiências, cada um estaria aprendendo melhor do que o professor ali na frente e explicar e depois passar um dever, eu acho que tem que haver uma dinâmica pra aquilo entrar na cabeça do aluno, porque num é chegando e explicando a matéria e jogando o exercício que o aluno vai aprender, ele tem ter um certo debate, pra aquilo não sair da cabeça dele (ESTUDANTE L).

grupo interage aí quem tiver as dúvida lá...um explica pro outro (ESTUDANTE JF).

vai no fundo do baú mesmo, ele vai lá na raiz; eu gosto disso...e outra que ele coloca pra trabalhar em grupo, isso quer dizer, troca de informações, de diálogo, de experiências uns com os outros e isso fica mais fácil... individualmente ele chama as pessoas na sua mesa pra tirar dúvidas né...do dia a dia, do que aconteceu, uma matemática do dia a dia, e isso é muito importante e depois, além disso, usar termos práticos (ESTUDANTE M).

Os olhares sobre a aprendizagem que aqui estão colocados pelos educandos e educadores vêm ao encontro do que temos defendido ao longo deste artigo. As percepções dos estudantes e educadores em relação a elementos que colaboram para tornar as aprendizagens escolares mais efetivas apontam para a necessidade de compreender que não há real possibilidade de entendermos a educação fora do processo de ressignificação das relações humanas, as quais devem colocar o diálogo entre os sujeitos como o centro da construção da autonomia, da democracia e da vida em comunidade. Não é possível pensar a prática educativa libertadora, que nos leva ao acesso aos conhecimentos historicamente construídos pela humanidade de forma consciente e crítica, sem o diálogo aberto e respeitoso entre as pessoas. A isso Rancière (2005) chama igualdade, quando há o reconhecimento de que não há uma pessoa sequer que não saiba muitas coisas e desconheça outras tantas.

Trabalhar na perspectiva do diálogo e da igualdade, no entanto, não é tarefa fácil a ser empreendida, especialmente se considerarmos as condições de formação e de trabalho em que os professores da EJA geralmente estão inseridos. Contexto este que dificilmente permite momentos de diálogo e troca de experiências entre docentes, tempo para planejamento coletivo e individual, entre outros desafios. A superação destes desafios em termos de políticas públicas e organização dos sistemas de ensino ainda é muito distante, embora haja avanços, fazendo com que o exercício de práticas diferenciadas restrinja-se ao engajamento pessoal de educadores da EJA, sempre que possível. Aliado a isto, percebe-se que, de modo geral, o paradigma de educação que prevalece nas práticas pedagógicas cotidianas ainda é tradicional, com foco no professor. Podemos evidenciar resquícios deste paradigma nas falas de alguns educadores, descritas a seguir.

é igual aquele negócio, é...eu ensino, passo de um jeito, pego um exercício na apostila passo igualzinho, a gente vai corrige, na prova passo aquele mesmo exercício só mudo alguns valores e num vai...(EDUCADOR G).

eu acho que falta também, como ele falou, é você tirar tempo pra praticar, pra ver os detalhes, porque você viu o conteúdo aqui, seja qualquer um, de qualquer disciplina: viu o conteúdo "eu acho que eu já aprendi", vou pra casa num olho mais, esqueço, uma semana depois a pessoa já esqueceu, agora se ela começar a revisar... (EDUCADOR M).

Estas falas, de certa forma, apresentam-se como exemplos de práticas que desvinculam os conteúdos escolares do contexto em que estão inseridos, dos conhecimentos advindos da experiência. São exemplos da prática pedagógica focada no papel do professor explicador, modelo questionado ao longo deste trabalho, através dos autores trazidos como referência.

Sendo assim, embora todos os educadores, na concepção, assumam e reconheçam a valorização dos saberes dos educandos como princípio potencializador de aprendizagens mais significativas e de relações mais igualitárias e humanas dentro do ambiente escolar, e trabalhem para isto, na prática, ainda encontram dificuldades em desenvolver posturas e métodos que condizam com este pensamento, sendo este um desafio no qual é preciso se lançar diariamente.

\section{CONSIDERAÇõES FINAIS}

Os cursos de PROEJA FIC são espaços riquíssimos para o desenvolvimento de experiências pedagógicas que se configuram como alternativa ao modelo vigente de se pensar e fazer educação, por articularem conteúdos e disciplinas da formação geral à qualificação profissional e terem como público-alvo estudantes da 
Educação de Jovens e Adultos. Nesse sentido, todas as pesquisas que contribuem para o fortalecimento de currículos integrados, planejamentos coletivos, materiais didáticos significativos, metodologias e práticas avaliativas diferenciadas podem colaborar positivamente para a formação dos educadores envolvidos na implementação deste programa. Nesta pesquisa mantivemos o foco em trazer os olhares de professores a respeito de suas práticas bem como dos educandos sobre seus processos de aprendizagem no que diz respeito, especificamente, ao reconhecimento dos saberes e experiências adquiridas ao longo da vida.

Os dados coletados e analisados nos orientam no sentido de dar visibilidade a algumas ações já implementadas pelos professores no cotidiano do curso investigado que valorizam a participação dos estudantes, fazendo o esforço de tornar os conteúdos a serem ensinados mais reais e próximos a suas realidades. Indicam também que muito ainda é possível e necessário de ser feito no sentido de colocarmos em prática os princípios de uma educação verdadeiramente igualitária e libertadora.

Longe de apresentar receitas, buscamos confirmar um caminho já apontado por diversos pesquisadores da educação e da Educação de Jovens e Adultos, alguns deles inclusive citados ao longo do artigo, que é o de valorização do educando como sujeito de muitos conhecimentos e, portanto, capaz de participar ativa e conscientemente na construção de novos saberes.

\section{REFERÊNCIAS}

BRASIL. Documento Base Programa Nacional de Integração da Educação Profissional com a Educação Básica na Modalidade de Educação de Jovens e Adultos. Brasília: [S.n.], 2007.

ESTEBAN, Maria et al. Avaliação: uma prática em busca de novos sentidos. Rio de Janeiro: DP\&A editora, 2001. FREIRE, Paulo. Extensão ou Comunicação? Rio de Janeiro: Paz e Terra, 1971.

1996.

Pedagogia da autonomia: saberes necessários à prática educativa. 31 ed. São Paulo: Paz e Terra,

. Pedagogia do Oprimido. 17ạ. ed. Rio de Janeiro: Paz e Terra, 1987.

FREITAS, Rony Cláudio de Oliveira. Produções colaborativas de professores de matemática para um currículo integrado do PROEJA-IFES. (2010. 306 f.) Tese (Doutorado em Educação) - Programa de Pós-Graduação em Educação, Universidade Federal do Espírito Santo. Vitória, 2010.

JORDANE, Alex. Uma experiência de (Trans)formação de uma professora de matemática: análise de um trabalho colaborativo. (2007. 155 f.) Dissertação (Mestrado em Educação) - Programa de Pós-Graduação em Educação da Faculdade de Educação da Universidade Federal de Minas Gerais. Belo Horizonte, 2007.

KUENZER, Acacia Zeneida (Org.). Ensino Médio: construindo uma proposta para os que vivem do trabalho. 6. ed. São Paulo: Cortez, 2009.

OLIVEIRA, Inês Barbosa. Tendências recentes dos estudos e das práticas curriculares. Disponível em $<$ http://www.ia.ufrri.br/ppgea/conteudo/conteudo-2009-2/1SF/Tendencias praticas curriculares.pdf $>$. Acesso em 18 ago. 2010.

OLIVEIRA, Marta Kohl. Jovens e Adultos como sujeitos de conhecimento e aprendizagem. In.: RIBEIRO, Vera Masagão (Org.). Educação de jovens e adultos: novos leitores, novas leituras. Campinas, SP: Mercado de Letras; São Paulo: Ação Educativa, 2001.

PICONEZ, Stela C. Bertholo. Educação escolar de jovens e adultos. 6. ed. Campinas, SP: Papirus, 2002.

PIMENTA, Selma Garrido. GHEDIN, Evandro. FRANCO, Maria Amélia Santoro (Orgs.). Pesquisa em educação: alternativas investigativas com objetos complexos. São Paulo: Loyola, 2006.

RANCIÉRE, Jacques. O mestre ignorante: cinco lições sobre a emancipação intelectual. 2 ed. Belo Horizonte:Autêntica, 2005.

SKOVSMOSE, Ole. Educação matemática crítica: a questão da democracia. Campinas, SP: Papirus, 2001.

SOLIGO, Rosaura. Dez questões a considerar. Disponível em <http://www.tvebrasil.com.br/salto/boletins2001/lee/leetxt1.htm>. Acesso em: 13 jul. 2010.

UNESCO. Educação de jovens e adultos: uma memória contemporânea, 1996-2004. Brasília: [S.n.], 2004. 